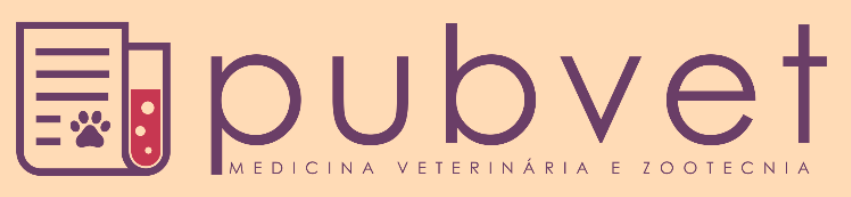

https://doi.org/10.31533/pubvet.v13n6a344.1-7

\title{
Medicina veterinária de mega catástrofes no Brasil: história e despreparo repetidos
}

\author{
Marcos Vinícius de Souza $^{1} \bullet$ \\ ${ }^{1}$ M.V.; D.Sc.; M.Sc.; Pós-Doutorando, Universidade Federal de Uberlândia, Brasil. ${ }^{*}$ E-mail para correspondência: \\ mvscardoso@yahoo.com.br
}

\begin{abstract}
Resumo. A Medicina Veterinária de Catástrofes ainda é muito incipiente em nosso país e, por esse motivo, todas as informações geradas a respeito de intervenções pré e póscatástrofes devem ser publicadas a fim de se mitigar com maior eficiência possíveis futuras calamidades. Com a intensificação da intervenção do homem sobre os ecossistemas, muitos são os riscos criados para a saúde ecológica. De modo geral, tais situações acontecem de forma abrupta advindas de um fenômeno adverso previsível ou não, para o ser humano, os animais e o meio ambiente, que requerem ações imediatas de mitigação dos efeitos negativos ocasionados. Fica cada vez mais clara a necessidade de se especializar e reconhecer a área de atuação de profissionais na "Medicina Veterinária Tática, de Desastres e Catástrofes", uma vez que as condutas ligadas a tais situações são distintas das demais áreas da medicina veterinária e possuem caráter emergencial.
\end{abstract}

Palavras-chave: Brumadinho - MG, Vale, barragem de rejeitos, medicina de catástrofe, desastres

\section{Mega catastrophe veterinary medicine in Brazil: repeated history and disregard}

\begin{abstract}
The Veterinary Medicine of Catastrophes is still very incipient in our country and, for that reason, all the information generated about pre and post disaster interventions must be published in order to more efficiently mitigate possible future calamities. With the intensification of human intervention on ecosystems, many risks are created for ecological health. In general, such situations occur abruptly due to an adverse phenomenon that is foreseeable or not, for humans, animals and the environment, which require immediate actions to mitigate the negative effects. It becomes increasingly clear the need to specialize and recognize the area of expertise of professionals in the "Veterinary Medicine Tactical, Disasters and Catastrophes", since the procedures associated with such situations are distinct from the other areas of veterinary medicine and have an emergency character.
\end{abstract}

Keywords: Brumadinho - MG, Vale, tailings dam, catastrophe medicine, disasters

\section{Medicina veterinaria de mega catástrofes en Brasil: historia y despreparos repetidos}

Resumen. La Medicina Veterinaria de Catástrofes sigue siendo muy incipiente en nuestro país y, por ese motivo, toda la información generada acerca de intervenciones pre y postcatástrofes deben ser publicadas a fin de mitigar con mayor eficiencia futuras calamidades. Con la intensificación de la intervención del hombre sobre los ecosistemas, muchos son los riesgos creados para la salud ecológica. En general, estas situaciones ocurren de forma abrupta derivadas de un fenómeno adverso previsible o no, para el ser humano, los animales y el medio ambiente, que requieren acciones inmediatas de mitigación de los efectos 
negativos ocasionados. Se hace cada vez más clara la necesidad de especializarse y reconocer el área de actuación de profesionales en la "Medicina Veterinaria Táctica, de Desastres y Catástrofes", ya que las conductas ligadas a tales situaciones son distintas de las demás áreas de la medicina veterinaria y poseen carácter de emergencia.

Palabras clave: Brumadinho - MG, Valle, represa de desechos, medicina de catástrofe, desastres

\section{Introdução}

No ano de 2013 ocorreram 330 desastres naturais no mundo, sendo a menor incidência da última década. O total de humanos afetados foi de 96,5 milhões, também inferiores quando comparado com a média anual de 215,8 milhões no último decênio (Guha-Sapir et al., 2013). A Organização Mundial de Saúde (OMS) define como catástrofe qualquer acontecimento que cause estragos, desestabilização econômica, perda de vidas humanas e deterioração de saúde, a uma escala tal, que justifique uma mobilização excepcional de auxílios vindos de fora da comunidade e da zona atingida e enfatiza o elemento específico da Medicina de Catástrofe: a insuficiência temporária de recursos para responder às necessidades locais (Bandeira, 2008).

A Medicina de Catástrofe não é uma especialidade médica no seu sentido mais estrito, mas é considerado um ramo específico da medicina, que lida com emergências extremas. Seu contexto pode ser caracterizado como cenários difíceis, de alto risco e com quantidades maciças de vítimas que necessitam de rápida triagem e intervenção (Al-Sleibi, 2010).

Chama-se de desastres de massa os acidentes coletivos nos quais se verifica grande número de vítimas graves ou fatais. Na maioria das vezes, esses são decorrentes da forma de convivência humana, levada a habitar áreas geográficas reduzidas e com alto índice de concentração demográfica. Adicionalmente, o avanço incontrolável das disponibilidades tecnológicas com a criação do que se rotulou de "risco proveito" ou "risco criado", conhecido e avaliado, mas de que ninguém abre mão, criou uma "tecnologia de catástrofe". Assim, a conveniência humana em dispor de grandes edificações, dos deslocamentos em transportes coletivos cada vez mais rápidos, do uso indiscriminado de algumas modalidades de energia e do emprego assustador de substâncias nocivas ocasiona a possibilidade amarga das grandes tragédias e, por isso, pode-se dizer que o homem atual vive a "era do risco" (França, 2009).

A história ensina que as catástrofes irão acontecer, mesmo sem ser possível determinar o momento, o local e as características, não sendo previsível qual a forma do "cisne negro". Por isso, o planejamento tem por base o passado conhecido e as lições aprendidas (Santos, 2013). Nos desastres frequentemente ocorre a ruptura da relação Homem-Animal uma vez que, na maioria dos casos, é negada a evacuação conjunta dos animais com os seus tutores, o que ocasiona a eventual morte ou perda do animal (Hunt et al., 2008).

Slaikeu et al. (1996) trabalha com o conceito de intervenção em crise e diferencia as crises em vitais, as quais são relacionadas aos ciclos do desenvolvimento humano, e em circunstanciais, que são repentinas, precipitadas por algum evento extremo e imprevisíveis. Por representar graves ameaças à saúde física e mental, as crises com frequência requerem assistências imediatas.

Segundo Ventura (2011), a intervenção em situações de emergência e desastre é composta por três etapas: preventiva, emergencial e pós-emergencial. Pode soar estranho falar em prevenção quando se trata de eventos inesperados ou mesmo imprevisíveis, contudo, em diversos aspectos, pode-se reduzir a probabilidade de ocorrência de desastres e/ou amenizar as consequências que o mesmo terá. Incluem-se aí ações direcionadas a avaliar e reduzir riscos, associadas a uma preparação coletiva, como acontece em regiões comumente atingidas por terremotos, por exemplo. Por isso, é extremamente importante a elaboração de políticas públicas para atender os objetivos citados, além disso, o desenvolvimento de políticas de Estado que proporcionem condições mínimas para uma vida digna, compondo uma rede efetiva de serviços e recursos acessíveis.

O objetivo deste trabalho é analisar os desastres envolvendo barragens e um breve panorama das ações promovidas até o momento no que tange aos animais no incidente do rompimento da barragem de rejeitos da Mina Córrego do Feijão, pertencente à mineradora VALE no munícipio de Brumadinho, MG, Brasil. 


\section{Relato de caso}

O histórico de rompimento de barragens no estado de Minas Gerais vai de 1986 a 2019, e se encontra resumido em ordem cronológica no Tabela 1.

Tabela 1. Histórico de rompimento de barragens em mineradoras do estado de Minas Gerais, Brasil

\begin{tabular}{|c|c|c|c|}
\hline Ano & Barragem & Município & Consequências \\
\hline 1986 & Mina de Fernandinho & Itabirito & 7 pessoas mortas \\
\hline 1997 & Rio das Pedras & Rio Acima & $\begin{array}{l}82 \mathrm{~km} \text { de destruição ao longo do Rio das Velhas e deixou centenas de } \\
\text { pessoas desalojadas }\end{array}$ \\
\hline 2001 & Mineração Rio Verde & $\begin{array}{l}\text { Macacos (Nova } \\
\text { Lima) }\end{array}$ & $\begin{array}{l}5 \text { pessoas mortas, } 79 \text { hectares de Mata Atlântica foram devastados e o } \\
\text { soterramento de parte da comunidade de São Sebastião das Águas Claras }\end{array}$ \\
\hline 2003 & Ind. Cataguases de Papel & Cataguases & $\begin{array}{l}\text { Mortandade de peixes, interrupção do abastecimento de água em vários } \\
\text { munícipios e prejuízos de propriedades rurais }\end{array}$ \\
\hline 2007 & Rio Pomba Cataguases & Miraí & $\begin{array}{l}4.000 \text { pessoas desalojadas, inundações de áreas agricultáveis, mortandade } \\
\text { de peixes e desabastecimento de água em munícipios vizinhos }\end{array}$ \\
\hline$\overline{2014}$ & Herculano Mineração & Itabirito & 3 pessoas mortas (funcionários) \\
\hline 2015 & $\begin{array}{l}\text { Barragem de Fundão } \\
\text { (Samarco) }\end{array}$ & Mariana & $\begin{array}{l}19 \text { pessoas mortas, devastou comunidades e deixou rastros em } 39 \\
\text { munícipios de Minas Gerais e Espírito Santo }\end{array}$ \\
\hline 2019 & $\begin{array}{l}\text { Barragem I da mina } \\
\text { Córrego do Feijão }\end{array}$ & Brumadinho & $\begin{array}{l}236 \text { pessoas mortas; } 34 \text { pessoas estão desaparecidas; } 395 \text { pessoas localizadas } \\
\text { com vida. }\end{array}$ \\
\hline
\end{tabular}

O complexo minerário (Mina Córrego do Feijão) da empreendedora Vale S.A., filial Vale do Paraopeba é formado pelas seguintes barragens: I (rompida), VI (em risco de rompimento), IV, IVA, Menezes I, Menezes II e VII. A barragem de rejeitos da Mina Córrego do Feijão se localizava no subdistrito do Córrego do Feijão, a 30,2 km do centro do munícipio brasileiro de Brumadinho, MG, Brasil. Seu rompimento ocorreu na tarde de 25 de janeiro de 2019 por volta das $13 \mathrm{~h} 20 \mathrm{~min}$. O rompimento dessa estrutura provocou o vazamento de aproximadamente $11.741 .325,34 \mathrm{~m}^{3}$ de rejeitos atingindo a bacia do rio Paraopeba. A soma total de rejeitos deste complexo minerário compreende 13.273.604,50 $\mathrm{m}^{3}$. Até a presente data foram contabilizadas 236 pessoas mortas; 34 pessoas desaparecidas; 395 pessoas localizadas com vida, sendo 222 funcionários da Vale e 173 terceirizados ou moradores da região e mais de 135 pessoas desabrigadas. Além de liderar o ranking mundial do maior desastre de barragem (Samarco - Mariana - MG) o Brasil também lidera o ranking mundial no quesito número de vítimas em acidentes com barragens.

Segundo dados da Agência Nacional de Mineração, a mina I tem como minério principal, o minério de ferro, e está classificada como categoria de risco baixo, dano potencial associado alto e classe B. A mina VI tem como minério principal o minério de ferro e está classificada como categoria de risco baixo, dano potencial associado alto e classe B. Ambas as minas estão inseridas na Política Nacional de Segurança de Barragens (Agência Nacional de Mineração, 2019).

O rompimento da barragem da Mina Córrego do Feijão é considerado o maior da história brasileira em termos de número de mortos. Um agravante da situação foi o não acionamento das sirenes instaladas em pontos críticos do entorno. Portanto, se existiam planos de contingência e rotas de fugas que permitissem aos moradores e aos animais se deslocarem para regiões seguras, os mesmos não puderam ser executados. Desde o rompimento da barragem, voluntários (Figuras 1 e 2), dentre eles, médicos veterinários, se mobilizaram no resgate e socorro aos animais atingidos pelo incidente. Diferentemente do que ocorreu no rompimento da barragem do Fundão, no município de Mariana, MG, em 2015, onde os animais foram atendidos de pronto, e vale ressaltar que os mesmos riscos de rompimento de outras barragens também existiam, os animais atingidos em Brumadinho após 36 horas ainda aguardavam socorro. Se passaram $72 \mathrm{hs}$ depois do momento do acidente sem a liberação para qualquer intervenção continuada na fauna doméstica e selvagem afetada. Visto que o risco de rompimento da barragem VI ainda existia e o grande número de pessoas desaparecidas demandava todo o contingente especializado, apenas vinte e seis animais foram resgatados até esse momento, como informado pela Mineradora Vale S.A. Outro ponto que é desfavorável ao atendimento veterinário imediato é o despreparo técnico para situações de calamidades, nas quais o médico veterinário poderia executar as suas ações em paralelo aos 
especialistas na área. Esse despreparo abre portas para a intervenção de civis sem orientação adequada (Figuras 2 e 3), o que pode agravar a situação dos animais (Figura 4) e do meio ambiente (Figura 5).

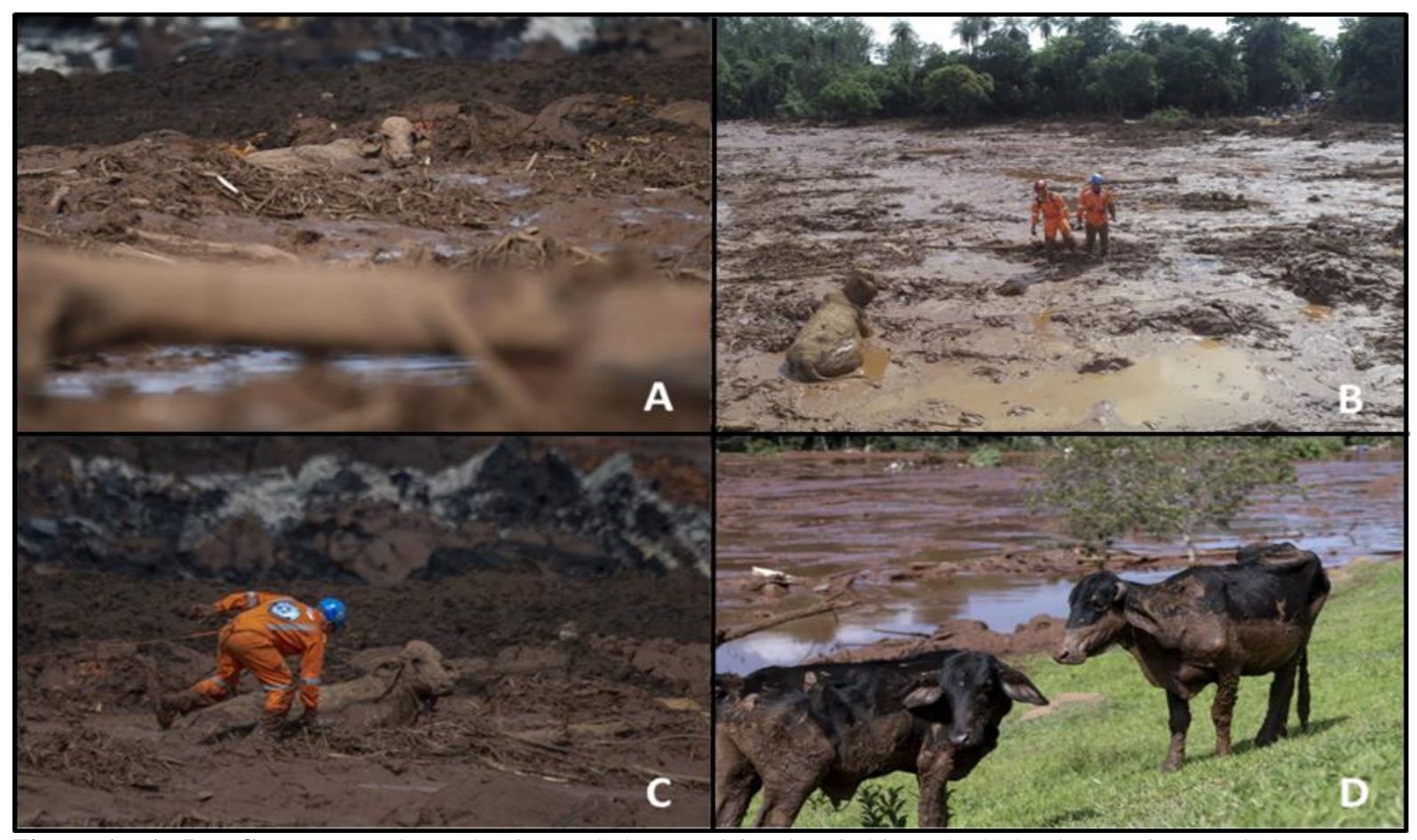

Figura 1. A, B e C - Resgate de um bovino atolado em rejeito de minério após 48 hs do rompimento da barragem na comunidade de Casa Grande, Brumadinho, MG, Brasil. Equipe de resgate formada por bombeiros militares. Nota-se que a equipe tem que movimentar com todo o cuidado sobre a lama para evitar o atolamento; D - Dois bovinos cobertos de detritos de mineração depois do rompimento da barragem. Fonte: Pimentel, M., Penner, A., Drumond, L. \& Magno, D. Portal G1. (2019).

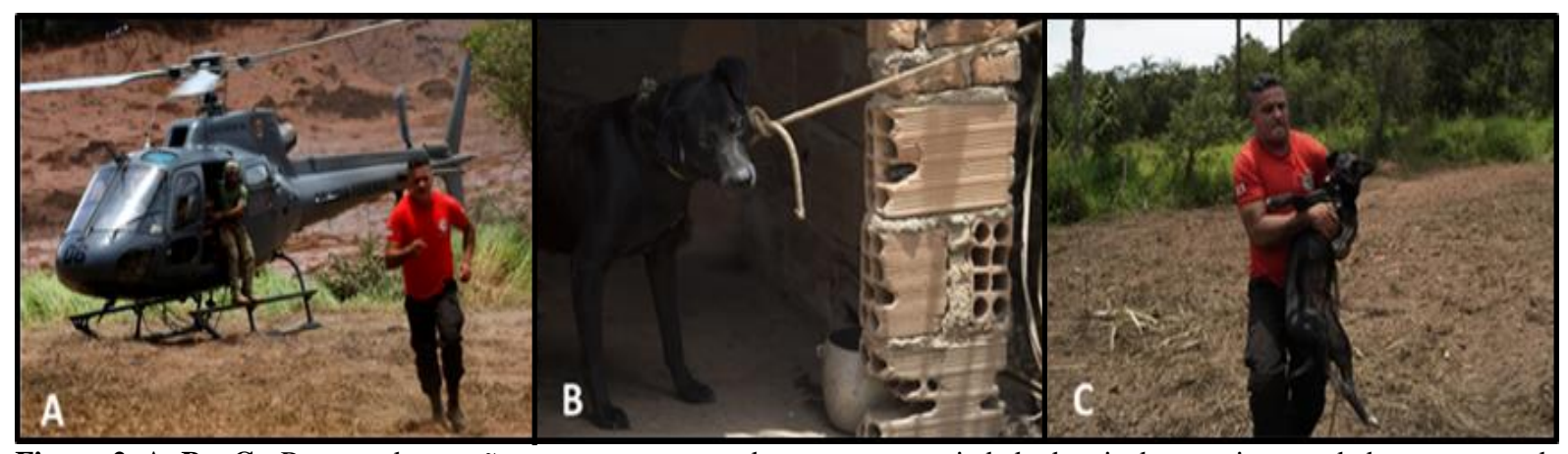

Figura 2. A, B e C - Resgate de um cão que estava amarrado em uma propriedade depois do rompimento da barragem sendo realizado por um voluntário (bombeiro civil) Brumadinho, MG, Brasil. Fonte: Machado, A. \& Correa, L. Portal G1. (2019)

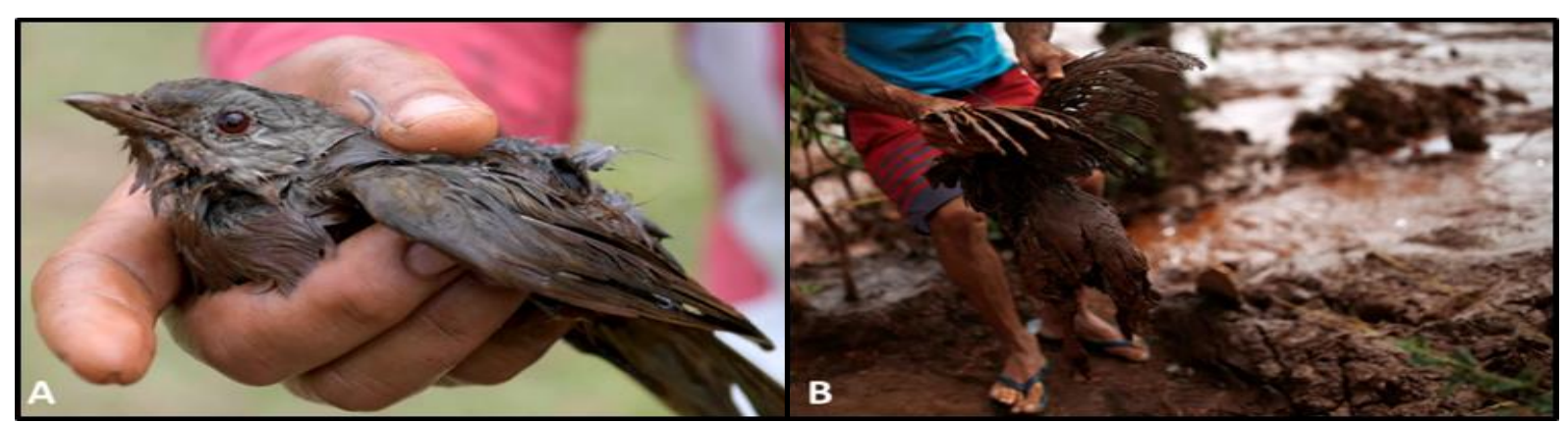

Figura 3. A - Passeriforme resgatado por um morador local, Brumadinho, MG, Brasil; B-Galiforme resgatado por um morador local. Fonte: Alves, W. \& Machado, A. Portal G1. (2019). 


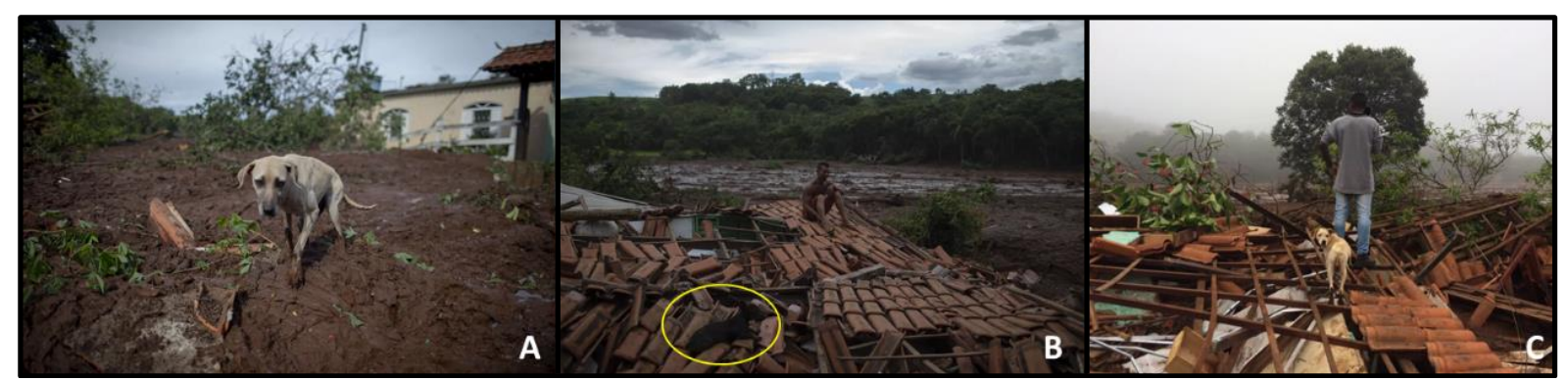

Figura 4. A - Imagem de um cão perambulando em meio à lama na comunidade de Parque da Cachoeira, Brumadinho, MG, Brasil. B - Imagem de um cão (círculo amarelo) com seu proprietário em cima do telhado. O mesmo está protegendo o que restou dos pertences da família de sauquadores e $\mathbf{C}$ - Imagem de um cão sobre o telhado e um homem olhando a destruição Fonte: Paulo, P. P. \& Pimentel, P. Portal G1. (2019).

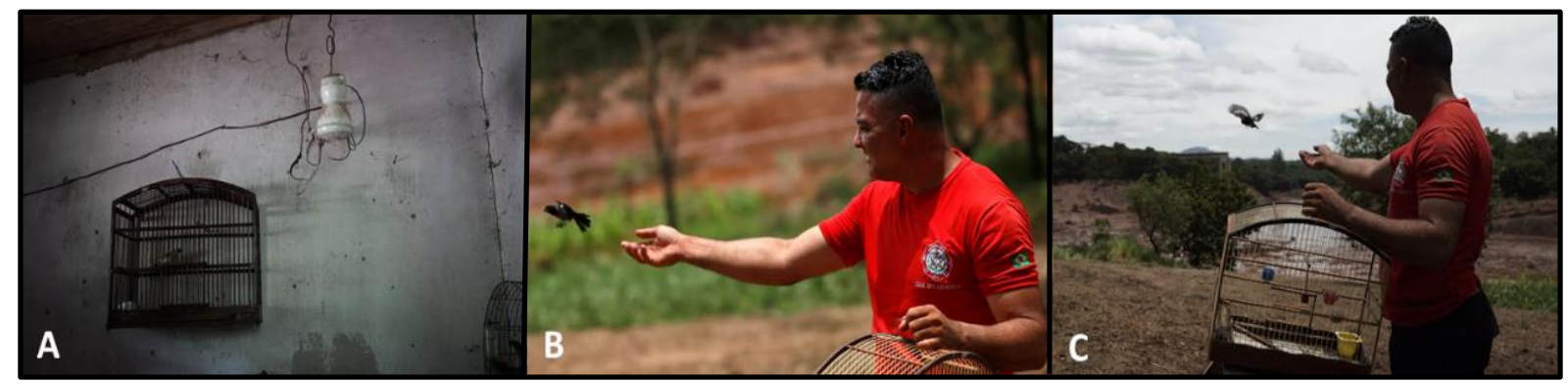

Figura 5. A - Imagem de passeriformes que foram resgatados por voluntário (bombeiro civil) 48 hs após o rompimento da barragem, Brumadinho, MG, Brasil. B e C - Imagem de passeriforme cativo sendo solto após ser resgatado por voluntário (bombeiro civil) e a soltura sendo realizada sem nenhum critério técnico científico para tal. Fonte: Machado, A. \& Correa, L. - Portal G1. (2019).

Após 33 anos do episódio do rompimento da primeira barragem no estado de Minas Gerais e do maior desastre ambiental da história mundial em 2015 (Samarco - Mariana, MG), o qual se tornou um marco histórico para as mudanças nas legislações ligadas às atividades de mineração, ainda não houve um progresso da Medicina Veterinária Tática, de Desastres e Catástrofes no Brasil.

Outro ponto importante a ser exposto é o apoio médico-veterinário aos cães de busca e salvamento (Figura 6). Segundo Fenton (1992), os cães de busca e salvamento (SAR) e os seus guias, ditos binômios, têm um papel fulcral nas operações de busca e salvamento assegurando uma rápida detecção e resgate de vítimas, graças a sua grande capacidade olfativa. Seria necessário somar as células olfativas de 44 humanos para igualar às presentes, em média, num canídeo da raça pastor alemão.

Os cães de busca e salvamento estão expostos a riscos físicos e químicos que podem prejudicar sua performance e colocar suas vidas em risco. Portanto, há a necessidade oferecer uma estrutura de apoio, constituída por médico veterinários e demais voluntários, que possam dar respostas de forma rápida em termos clínicos e/ou cirúrgicos a tais animais, que são indispensáveis ao sucesso na busca de vítimas de desastres.

Apesar de polêmica, há também a necessidade de considerar a prática de eutanásia aos animais que dela necessitam. A Resolução № 1000, de 11 de maio de 2012 do Conselho Federal de Medicina Veterinária (CFMV) dispõe sobre procedimentos e métodos de eutanásia em animais e dá outras providências - considerando que a eutanásia é um procedimento clínico e sua responsabilidade compete privativamente ao médico veterinário; considerando que a eutanásia é um procedimento necessário, empregado de forma científica e tecnicamente regulamentada, e que deve seguir preceitos éticos específicos, e considerando que os animais submetidos à eutanásia são seres sencientes e que os métodos aplicados devem atender aos princípios de bem-estar animal. "O parágrafo I do Art. $3^{\circ}$ afirma que se o bem-estar do animal estiver comprometido de forma irreversível, a eutanásia é considerada como um meio de eliminar a dor ou o sofrimento, os quais não podem ser controlados por meio de analgésicos, de sedativos ou de outros tratamentos".

Alguns animais foram abatidos e dentre eles um bovino (Figura 7) que foi submetido ao abate após passar várias horas atoladas no rejeito em Brumadinho. $\mathrm{O}$ mesmo foi abatido a tiros de uma aeronave 
por um agente público de segurança. Dentro de um cenário caótico no qual não existem previsões de prazo para o resgate dos animais atolados no rejeito de minério, os mesmos devem receber todos os cuidados necessários até que o resgate possa ser efetuado. Caso as condições clínicas do animal não permitam o seu resgate, o procedimento de eutanásia deve ser realizado seguindo os preceitos desta resolução (Resolução No 1000, de 11 de maio de 2012 - CFMV) e do bem-estar animal.

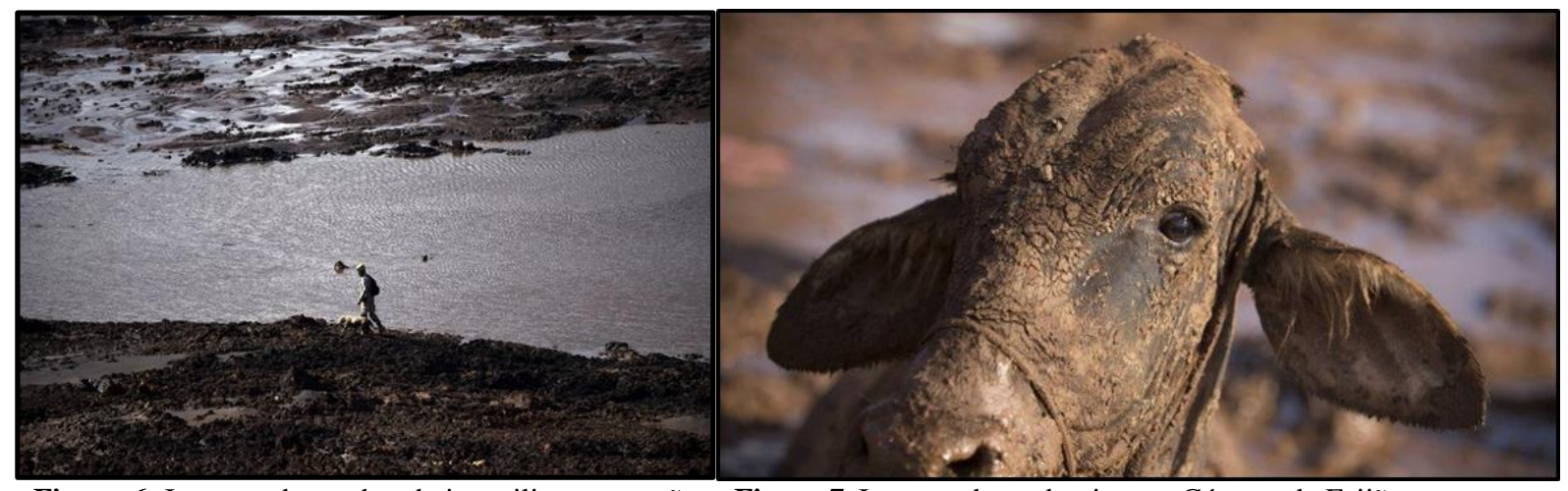

Figura 6. Imagem de um bombeiro militar e seu cão de resgate a procura de corpos na região do Córrego do Feijão, Brumadinho, MG, Brasil Fonte: Magno, D. - Portal G1. (2019).

Figura 7. Imagem de um bovino em Córrego do Feijão que passou por procedimento de eutanásia 72 horas após o desastre, Brumadinho, MG, Brasil. Fonte: Foletto, M.- Portal de notícias o globo. (2019).

Das lições aprendidas com o rompimento da barragem de rejeitos de Fundão quase nada se alterou em termos de dificuldades da equipe nos aspectos logísticos, ligados à busca, resgate, transporte, instalações. Vale ressaltar que $72 \mathrm{hs}$ após o rompimento da barragem ainda não existia um Centro de Recolhimento Avançado de Saúde Animal (CRASA). Ressalta-se ainda que não existe no Brasil a nível de Medicina Veterinária Tática, de Desastres e Catástrofes treinamentos específicos e se quer um plano de ação.

Visto que os desastres e catástrofes exigem rapidez na resposta, esse não é o melhor momento para se iniciar um processo de aprendizagem entre os profissionais Médicos Veterinários que irão intervir. Não existe hoje no Brasil nenhum especialista Médico Veterinário para a coordenação ou execução de intervenções desta e de outras magnitudes. Há somente alguns profissionais com vivência pessoal por participarem de ações de resgates em enchentes e do rompimento da barragem da Samarco, em Mariana, MG.

\section{Conclusões}

Embora as catástrofes de origem natural ou antropogênica sejam fenômenos imprevisíveis, existem padrões que se repetem e que podem prever as necessidades que irão surgir, principalmente no que tange à assistência médica veterinária aos animais e o modo como essas irão evoluir.

Em momentos de calamidades e por não existir em nosso país equipes estaduais de resposta rápida, toda a ajuda com o nível adequado de conhecimento deve ser absorvida de pronto. Mais uma vez é possível concluir que o poder público e principalmente o CFMV precisam assumir o gerenciamento de tal atividade a nível nacional. Além de confeccionar uma resolução acerca do tema, o CFMV deve estimular a execução e gerenciamento de equipes de respostas rápidas no território nacional, além de realizar o aperfeiçoamento continuado a médicos veterinários e intermediar a interação com outras áreas afins e com as estruturas civis, públicas, privadas, ou não governamentais, com o intuito de se articular melhor ao auxílio aos animais vítimas de catástrofes.

\section{Referências bibliográficas}

Agência Nacional De Mineração. Acesso em: 28 janeiro de 2019, disponível em: http://www.anm.gov.br/assuntos/barragens/cadastro-nacional-de-barragens-de-mineracao.

Al-sleibi, N. (2010) Excerto da Mensagem do Secretário-Geral da Organização Internacional de Proteção Civil. Acesso em: 07 março de 2016, disponível em: http://www.proteccaocivil.pt/List/Foco/Attachments/49/OIPC\%20-\%20DIA\%20PC\%202010\%20(2).pdf 
Bandeira, R. (2008). Medicina de catástrofe. Porto, Portugal: Editora da Universidade do Porto.

Fenton, V. (1992). The use of dogs in search, rescue and recovery. Journal of Wilderness Medicine, 3(3):292-300.

França, G. V. (2009) Desastres de Massa - Sugestões para um itinerário correto de auxílios. Acesso em: 06 março de 2016, disponível em: http://revistabioetica.cfm.org.br/index.php/revista_bioetica/article/view/471, 1994.

Guha-Sapir, D., Hoyos, P. \& Below R. (2013) Annual disaster statistical review. Acesso em: 06 março de 2016, disponível em: http://cred.be/sites/default/files/ADSR_2013.pdf.

Hunt, M., Al-Awadi, H. \& Johnson, M. (2008). Psychological sequelae of pet loss following Hurricane Katrina. Anthrozoös, 21(2):109-121.

Portal de notícias o globo. (2019). Acesso em: 28 janeiro de 2019, disponível em: https://oglobo.globo.com/brasil/atolada-na-lama-vaca-sacrificada-em-brumadinho-23407022.

Portal G1. Acesso em: 28 janeiro de (2019), disponível em: https://g1.globo.com/mg/minasgerais/noticia/2019/01/25/barragem-da-vale-se-rompe-em-brumadinho-mg-fotos.ghtml.

Resolução $\mathrm{N}^{\mathrm{o}}$ 1000, de 11 de maio de (2012). Acesso em: 28 janeiro de 2019, disponível em: http://portal.cfmv.gov.br/lei/index/id/326.

Santos, N.O.C.L. (2013). A medicina de catástrofes na marinha. A resposta da medicina naval em caso de catástrofe. Pedrouços. Trabalho de investigação individual do curso de promoção de oficial general. Instituto de Estudos Superiores Militares.

Slaikeu, K. A., Mejía, M. C. \& López, M. E. G. (1996). Intervención en crisis: Manual para práctica e investigación. México: Manual Moderno México.

Ventura, R. (2011). Os impactos das emergências e dos desastres na política de Assistência Social. In: Conselho Federal de Psicologia. Psicologia de emergências e desastres na América Latina: promoção de direitos e construção de estratégias de atuação. Brasília: CFP, 2011.

Recebido: 9 de maio, 2019.

Aprovado: 24 de maio, 2019.

Publicado: 27 de junho, 2019.

Licenciamento: Este artigo é publicado na modalidade Acesso Aberto sob a licença Creative Commons Atribuição 4.0 (CC-BY 4.0), a qual permite uso irrestrito, distribuição, reprodução em qualquer meio, desde que o autor e a fonte sejam devidamente creditados. 